\title{
UM CLICK NA ESCOLA: OLHARES E DISCURSOS DE JOVENS ESTUDANTES SOBRE A INSTITUIÇÃO ESCOLAR CONTEMPORÂNEA
}

\author{
Suzana Feldens Schwertner ${ }^{1}$, Jaqueline Maria Conrad ${ }^{2}$
}

\begin{abstract}
Resumo: $\mathrm{O}$ presente artigo tem como objetivo analisar imagens produzidas por estudantes concluintes do Ensino Médio e Fundamental acerca das funções da escola na contemporaneidade. Por meio de estudos pós-estruturalistas em Educação, problematizam-se os conceitos de educação e aprendizagem, articulando-os ao olhar dos jovens sobre as práticas na instituição escolar. A metodologia foi composta por grupos focais, em duas escolas do Vale do Taquari (RS), envolvendo 35 participantes. Por meio da análise das imagens, percebemos a importância da escola na vida dos estudantes, em suas funções pedagógicas, políticas e sociais, destacando o espaço da biblioteca, a aprendizagem no grupo de colegas e as relações de amizade. Enfatiza-se, ao final, a necessidade de possibilitar espaços de escuta aos jovens, apostando no seu potencial criativo, argumentativo e questionador.
\end{abstract}

Palavras-chave: Escola. Fotografia. Jovens. Contemporaneidade.

\section{A CLICK AT SCHOOL: YOUNG STUDENTS' VIEWS AND DISCOURSES ABOUT THE CONTEMPORARY SCHOOL INSTITUTION}

\begin{abstract}
This paper aims to analyze images produced by senior Elementary and High School students concerning the functions of the school in contemporaneity. By means of post-structuralist studies in Education, it problematizes the concepts of education and learning by articulating them with the way young people regard the school practices. The methodology involved focus groups in two schools in Taquari Valley (RS), with 35 participants. The analysis of the images evidenced the importance of the school in the students' lives, with its pedagogical, political and social functions, with an emphasis on the library, group learning, and friendship. Finally, the need of providing settings to listen to the youths is emphasized considering their creative, argumentative and questioning potential.
\end{abstract}

Keywords: School. Photography. Youth. Contemporaneity.

1 Psicóloga. Doutora em Educação. Docente do Curso de Psicologia e do Mestrado em Ensino Centro Universitário UNIVATES.

2 Acadêmica do Curso de Psicologia. Bolsista de Iniciação Científica FAPERGS e do Centro Universitário UNIVATES. 


\section{INTRODUÇÃO}

O presente trabalho foi proposto a partir do projeto de pesquisa "A escola e as novas configurações da contemporaneidade: a voz de estudantes concluintes do Ensino Médio e Fundamental" (MCTI/CNPQ/Universal 14/2014), vinculado ao Mestrado em Ensino do Centro Universitário UNIVATES. Tem como objetivo principal analisar, a partir do olhar e discursos dos estudantes, as funções da escola na contemporaneidade. Igualmente, busca valorizar a escuta e o espaço de produção dos alunos em meio a uma escola que vem sendo chamada, cada vez mais, a cumprir diferentes papeis e funções. Como os estudantes - especialmente aqueles em momento de conclusão de curso entendem as configurações desta escola na atualidade?

A pesquisa apresenta como aporte teórico o estudo de autores como Michel Foucault (2015; 2002), Júlio Groppa Aquino (2000), Jorge Larrosa (2000; 2004). Trata-se de uma pesquisa de cunho qualitativo que propõe um trabalho de discussão coletiva com os estudantes, por meio de grupo focal (GATTI, 2005) e photo elicitation (BANKS, 2001). Os estudantes são convocados a pensar sobre a participação da escola em suas vidas e a produzir uma fotografia sobre as funções e os sentidos da instituição escolar na atualidade. Esta investigação teve início no ano de 2014 e segue em andamento até 2017.

O presente artigo busca apresentar os resultados produzidos no ano de 2015, por meio da análise de dois encontros do grupo focal, destacando o momento de produção de imagens fotográficas dos estudantes. Para estas reflexões, foram utilizados os estudos de Paula Sibilia (2012), Gert Biesta (2013) e Jan Masschlein e Maarten Simons (2014), em consonância com investigações sobre análise de imagens propostas por Alves e Sgarbi (2001), Rego (2003) e Fischman e Sales (2014).

Escutar a voz dos estudantes, abrir espaço para a produção de discursos acerca da escola e de sua participação na vida dos jovens parece ser também algo pelo qual movimentos estudantis têm lutado neste momento em que vivemos (2016). Diversas têm sido as mobilizações de estudantes, não apenas no Estado do Rio Grande do Sul, mas em nível nacional, em prol da escola e dos direitos pela educação, seguindo as mobilizações e greves realizadas por docentes de escolas estaduais. Um exemplo disso é a quantidade de escolas públicas que vêm sendo ocupadas pelos estudantes (SPERB, 2016; VETORAZZO, 2016; TOMAZELA, 2016). Percebemos, nestas mobilizações, o quanto os estudantes estão buscando espaços de escuta dentro da escola e até mesmo fora dela, junto àqueles que a administram. $\mathrm{O}$ maior propósito tem sido, especialmente, na produção de sentidos deste espaço institucional na vida dos jovens, como destacam Pereira e Lopes (2016, p. 201):

A educação anda e sempre andou atrelada às transformações sociais, culturais, históricas, econômicas e políticas do país, ou seja, entender o sentido que a escola ocupa na vida dos jovens significa entender que eles estão dentro de uma instituição, inclusos e pertencentes a uma sociedade, que está inserida em um sistema com uma estrutura social estabelecida por interconexões e interferências, o 
qual influencia os processos educacionais desses jovens e os sentidos e significados atribuídos à escola por eles (PEREIRA; LOPES, 2016, p. 201).

Esses movimentos sociais e políticos estão relacionados diretamente com o cotidiano escolar; por isso, ao pensar a escola, precisamos levar em conta a relação entre jovens e a educação, tal como afirmam Sales e Vasconcelos:

Os contextos sociais, políticos e econômicos, mediados pela aleatoriedade e contingências da sociedade contemporânea, interferem sobremaneira nas relações da juventude com a educação escolar e perspectivas juvenis e, por conseguinte, nas trajetórias dos/as jovens (SALES; VASCONCELOS, 2016, p. 70).

Os estudantes não querem ser coadjuvantes na vida escolar: querem ser atores, querem falar e ser ouvidos, expor suas ideias, lutar por espaços para discussão das práticas e de seu cotidiano escolar. Estas são as primeiras ideias que apresentam o que se propõe com este artigo: analisar e discutir os discursos de jovens estudantes concluintes sobre a presença e a função da escola em suas vidas na contemporaneidade. Adiante, apresentamos os aportes teóricos que embasam o presente artigo, seguida das trilhas metodológicas percorridas para, na sequência, discutir os resultados do trabalho investigativo.

\section{REFLETINDO SOBRE O ENQUADRAMENTO}

Como já apontado na introdução deste trabalho, são diversos papeis e funções atribuídos à escola hoje: se espera dela a disponibilidade de um tempo legítimo de ensino e de aprendizagem, um espaço para aprender regras e normas de convivência, um meio fundamental na preparação de cidadãos de seu país, que respeitem os seres humanos em sua diversidade, que protejam os direitos dos animais e que se envolvam nos cuidados do meio ambiente. Que ela seja também um espaço propagador de cultura, que cuide da saúde de seu alunado e que a promova também neste local, atentando especialmente aos aspectos psicológicos de cada criança e jovem ali matriculado. E que não esqueça de seu entorno, que englobe a comunidade escolar nas discussões que ali acontecem e que produzam encontros constantes entre escola e família. E que também lembre de atentar para outros tantos temas de visibilidade na escola, tais como as discussões de gênero e raciais, a sexualidade, as tecnologias na educação.

Enfim, que cuide, que proteja, que oriente, que discipline, que ensine os conteúdos e mais uma série de outros tantos papeis. Além do mais, ressalta Rego (2003, p. 58), hoje ainda se espera que ela venha "oferecer oportunidade de ter acesso a informações e experiências novas e desafiadoras". Ou seja, ela precisa constantemente renovar-se e inovar-se para atender às demandas das novas gerações. Como se adequar a todas estas exigências, cumprir com todos estes papeis? O que seria, afinal, função da escola? 
Masschlein e Simons (2014) apresentam alguns elementos acerca do que seria característico do "escolar": disponibilizar um "tempo livre" para o estudo e servir como espaço potencial ao "transformar conhecimento e habilidades em "bens comuns" (p. 10). Os autores destacam as funções políticas, sociais e pedagógicas ao resguardar à escola um espaço que "[...] permite a alguém se desenvolver como um indivíduo e como cidadão, isento de quaisquer obrigações específicas relacionadas ao trabalho, familiares ou sociais" (MASSCHLEIN; SIMONS, 2014, p. 97). Ou seja, tais autores destacam a necessidade de uma atenção ao tempo presente da criança e do jovem, que a escola teria como função preservar e manter, o "aqui-e-agora". O que difere de uma ideia da escola como um instrumento de "preparação para o futuro", função amplamente propalada para esta instituição.

Como afirma Klein e Arantes (2016, p. 140), houve um tempo que a escola era considerada um espaço formativo do jovem para o mercado de trabalho, sendo que hoje a escolarização já não garante mais a entrada no mundo do trabalho: "Durante muito tempo, a escola foi concebida como espaço formativo dos jovens, capaz de ampliar suas experiências de vida e de inseri-los no mercado de trabalho".

Mas o que percebemos, hoje, são as críticas em relação a uma escola que não faz associações entre aquilo que os estudantes estão aprendendo e o que vão vivenciar após a escola, na vida acadêmica ou no mercado de trabalho, ou na educação de maneira geral. Conforme Masschlein e Simons (2014, p. 13), as especificidades do currículo escolar não possibilitam uma "conexão real com o mundo", não aparecem em sintonia com o modo como suas vivências são experimentadas nele. Como destacam os autores:

A escola não prepara seus alunos para a "vida real". Para alguns, isso significa que a escola não leva suficientemente em conta as necessidades reais do mercado de trabalho. Para outros, isso significa que a escola coloca ênfase demais na ligação entre a escola e o mercado de trabalho ou entre a escola e as exigências do sistema de ensino superior (MASSCHLEIN; SIMONS, 2014, p. 13).

Arriscamos a dizer que a proposta de inserção no mercado de trabalho segue em ampla difusão, mas igualmente hoje percebemos que a escola tem sido desafiada a ser um local que oportunize aos alunos vivências diferentes daquelas obtidas em seu grupo familiar, que amplie seus contatos, que produza outros encontros, que enfatize diferentes olhares e que possibilite a escuta de seus participantes.

Mesmo com todas as transformações que a escola tem passado desde a sua criação, ainda encontramos os tradicionais modos de funcionamento, após séculos de sua existência, como a exigência pelo rigor, pela disciplina, com ênfase na normatização, como ressaltado por Sibilia (2012):

[...] justamente essas crianças e adolescentes, que nasceram ou cresceram no novo ambiente, têm de se submeter todos os dias ao contato mais ou menos violento com os envelhecidos rigores escolares. Tais rigores alimentam as engrenagens oxigenadas dessa instituição de confinamento fundada há vários séculos e que, 
mais ou menos fiel a suas tradições, continua a funcionar com o instrumental analógico do giz e do quadro-negro, dos regulamentos e boletins, dos horários fixos e das carteiras alinhadas, dos uniformes, da prova escrita e da lição oral (SIBILIA, 2012, p. 51).

A autora provoca o leitor ao questionar se as escolas, hoje, teriam se tornado obsoletas, lançando um olhar antropológico e genealógico com a seguinte pergunta: "Para que serve a escola?" Para Sibilia, os modos de habitar a contemporaneidade pela jovem geração produzem conflitos quando se relacionam ao espaço escolar. O que estamos aqui discutindo não é a necessidade ou não destes rigores e sim questionamos sua validade e possibilidade na escola contemporânea, esta que não se vê mais tão compatível com os corpos e as subjetividades de crianças e jovens que a frequentam hoje.

Outro aspecto importante a mencionar nesta discussão sobre as funções da instituição escolar passa por se perguntar pelo discurso econômico e neoliberal que parece ter tomado conta dos espaços educacionais há mais de duas décadas (COMPTON; WEINER, 2008; BALL, 2008). A proposta por maximizar resultados de aprendizagem e otimizar os processos educacionais vêm recebendo críticas por uma série de autores. Masschlein e Simons (2014, p. 157) contestam que tal apelo: “[...] reduz a escola a uma instituição prestadora de serviço para o avanço da aprendizagem e, portanto, para satisfazer as necessidades individuais de aprendizagem e aperfeiçoar resultados individuais de aprendizagem".

Com esta afirmação, abrem espaço para a discussão sobre uma polarização entre educação e aprendizagem, em consonância com os estudos de Biesta (2013). Em contraposição a uma educação conservadora e tradicional, abrir-se-ia, no contemporâneo, oportunidade a uma "era da aprendizagem", que tomaria o estudante como centro e principal (quando não o único) ator no processo educacional. Aprender a aprender seria o mote desta era, em que o papel do professor seria tomado como facilitador. Para Masschlein e Simons, a educação centrada no professor parece ter estado "fora de moda":

\begin{abstract}
Atualmente, as instituições e os ideais, obviamente, perderam muito do seu significado, e a transferência de conhecimento e a educação centrada no professor estão fora de moda. Exatamente por causa disso, as escolas modernas estão sendo convertidas em ambientes de aprendizagem centrada no aluno (MASSCHLEIN; SIMONS, 2014, p. 107).
\end{abstract}

Nesta nova "linguagem de aprendizagem" (BIESTA, 2013) - e não se trata de dizer que a ênfase na aprendizagem não seja importante - parece se destacar a ideia de uma aprendizagem a longo termo, para toda a vida e que deve ser responsabilidade de cada indivíduo, aprendendo autonomamente. Os impactos desta nova linguagem da aprendizagem refletem no processo de ensino ao se considerar a educação como uma mercadoria que deve satisfazer as necessidades individuais de cada um - sem considerar 
um dos pontos mais fundamentais da relação educacional, que é levar em conta os processos sociais e interpessoais.

O que é especial na relação educacional, conforme Biesta (2013), é a responsabilidade pela subjetividade do estudante, que é singular e única e que merece ser investida pela escola. Pois, como destacam Masschlein e Simons (2014, p. 9798), diferentemente de uma socialização, “[...] formar e educar uma criança tem a ver com algo fundamentalmente diferente. Trata-se de abrir o mundo e trazer o mundo (palavras, coisas e práticas que o compõem) para a vida. Isso é exatamente o que acontece no 'tempo escolar".

Partindo desta discussão inicial, nos perguntamos: como os jovens estudantes, em especial aqueles em momento de conclusão de uma fase de seu ensino escolar (no caso desta pesquisa, do Ensino Fundamental e Médio), percebem a escola contemporânea que vivenciam? $\mathrm{O}$ que podem nos contar e nos mostrar, por meio de fotografias, acerca da função da escola em suas vidas? Seguimos neste escrito apresentando as trilhas metodológicas percorridas nesta investigação para, na sequência, apresentarmos os resultados e discussões.

\section{LIGANDO AS CÂMERAS E AJUSTANDO O ÂNGULO}

Esta investigação está delineada como uma pesquisa de cunho qualitativo que propõe um trabalho de discussão coletiva com os estudantes, por meio da técnica de grupo focal (GATTI, 2005) e de foto elicitação (photo elicitation) proposta por Markus Banks (2001).

O grupo focal se caracteriza por uma discussão em torno de uma temática previamente selecionada - geralmente, o tema da pesquisa - a partir da qual uma questão central é lançada e a discussão entre os participantes permite que os mesmos exponham e confrontem suas ideias, pensamentos e opiniões. Permite, assim, por meio do contexto de interação produzido, que múltiplos pontos de vista possam surgir e se afetar, colocando os participantes em um espaço permanente de discussão e provocação - que talvez fosse difícil de criar em outros meios (GATTI, 2005). Contudo, o foco do grupo é sempre retomado, por mais que os debates possam promover, em certos momentos, um escape para outros temas ou assuntos que inicialmente não faziam parte da discussão.

A foto elicitação tem como objetivo envolver "[...] o uso de fotografias para evocar comentários, memória e discussão no decorrer de uma entrevista semiestruturada” (BANKS, 2009, p. 89). A partir de imagens previamente selecionadas ou produzidas pelos próprios sujeitos de pesquisa (como neste caso), os participantes discutem coletivamente as fotografias. Dessa forma, coloca-se os próprios estudantes como participantes ativos e responsáveis na investigação. 
Banks apresenta duas correntes presentes nas pesquisas que se utilizam das metodologias visuais: a primeiro delas, quando a criação de imagens é feita pelo próprio pesquisador, que produz a fotografia para documentar e analisar aspectos das interações e histórias pessoais dos sujeitos. Nesse processo, a discussão dos participantes ocorre independentemente de eles conhecerem as fotografias, compreenderem ou se interessarem por elas. A segunda corrente corresponde àquela em que as imagens são produzidas pelos próprios sujeitos de pesquisa, ou seja, a discussão parte das fotografias que os estudantes pensaram, elaboraram e fotografaram, onde "[...] o foco do projeto de pesquisa é mais obviamente visual, e os sujeitos de pesquisa têm, de forma mais evidente, uma conexão social e pessoal com as imagens" (BANKS, 2009, p. 21).

Segundo Torre e Murphy (2015), são muitos os benefícios produzidos pela foto elicitação: entre eles, destacamos o protagonismo dos participantes e a possibilidade de os pesquisadores compreenderem o tópico de estudo por meio do olhar dos sujeitos de pesquisa, que estabelecem com os pesquisadores relações de confiança. A foto elicitação permite a discussão coletiva dos materiais produzidos pelos próprios participantes, colocando-os como responsáveis pelos dados que estão sendo produzidos.

No caso desta pesquisa, além da produção da imagem, os estudantes assistem a todas fotografias em conjunto e debatem sobre as mesmas: o que chamou a atenção deles, ângulos, paisagens, detalhes e, ainda, questionam os colegas sobre o que pensaram na hora de fotografar a escola.

O tratamento dos dados foi realizado por meio da análise de imagens proposta por Fischman (2001); Fischman e Sales (2014) e Alves e Sgarbi (2011). Fischman e Sales (2014) nos alertam a considerar o contexto e circunstâncias em que cada imagem foi produzida, levando em conta as experiências e vivências de cada um dos estudantes no espaço da escola.

Alves e Sgarbi, ao analisar fotografias no espaço da escola, compreendem o ambiente escolar como um lugar de relações múltiplas e, por isso, toda a análise realizada sobre uma fotografia estará levando em consideração a "sua potência histórica e sua beleza que só a arte sabe apresentar" (2001, p.11). A análise as imagens e discursos dos jovens estudantes nos apresentam histórias e sentidos sobre o ambiente da escola: seus desejos, seus interesses, suas definições sobre a presença deste espaço em suas vidas. Ainda mais do que tudo isso, como nos mostram Alves e Sgarbi (2001, p. 99):

Uma fotografia revela muito mais do que as imagens do instante fotografado. Além do cenário, dos personagens e das leituras dos tempos e espaços aparentes, ela indica os vínculos e relações presentes nos textos imagéticos e revela, também, o seu autor: a intenção do fotógrafo e até, quem sabe, seus desejos, suas características, suas artes de fazer e de ser.

Durante o ano de 2015, foram realizados quatro encontros de grupos focais em duas escolas, uma da rede pública e outra da rede privada do Vale do Taquari (RS), com a participação total de 35 estudantes do $9^{\circ}$ ano do Ensino Fundamental e $3^{\circ}$ ano do 
Ensino Médio. Os grupos, que foram coordenados por dois participantes da pesquisa, aconteceram no espaço da escola, com duração média de uma hora. Todos os encontros, com exceção do terceiro, foram gravados e posteriormente transcritos na íntegra.

No primeiro encontro, os alunos foram questionados sobre as funções da escola; no segundo, investigamos o lugar ocupado pelas Ciências Exatas na escola. No terceiro encontro, foi proposta a produção de uma imagem sobre os sentidos e as funções da escola para os jovens estudantes. Eles também são orientados, neste momento, a elaborarem uma legenda para essa imagem. No quarto encontro, os estudantes assistiram coletivamente a cada uma das imagens produzidas, que foram então discutidas no grupo, retomando o objetivo da pesquisa. Na próxima seção discutiremos os resultados dessa investigação, apresentando os olhares e discursos dos jovens estudantes.

\title{
4 CLICK: FOTOGRAFIAS PRODUZINDO DISCURSOS
}

\begin{abstract}
Por um lado, então, temos a escola, com todo o classicismo que ela carrega nas costas; por outro, a presença cada vez mais incontestável desses "modos de ser" tipicamente contemporâneos. Tornou-se muito difícil evitar tamanha desarticulação com um olhar para o outro lado, ou um fingir que não há nada acontecendo, ou em buscar em vão remendar esse artefato abstruso que, ao que tudo indica, parece ter perdido boa parte de sua eficácia e seu sentido ao se deparar com a nova paisagem que cresceu a seu redor (SIBILIA, 2012, p. 16).
\end{abstract}

É por meio desta paisagem, observada atentamente pelos jovens estudantes, que iniciamos esta seção de análise. Procuramos, por meio das produções fotográficas e dos grupos focais, ouvir e contemplar o que os estudantes discutiram coletivamente sobre as imagens. Nesse sentido, ressaltamos o quanto as fotografias produzidas dizem sobre eles, sobre as vivências e experiências pessoais e coletivas de cada um no espaço da escola.

Destacamos o interesse dos estudantes na produção das fotografias: mesmo familiarizados com as imagens que os cercam cotidianamente, pelo uso intenso da câmera dos celulares - com a qual produzem muitas fotografias -, o uso da câmera fotográfica entusiasmou os participantes a produzir as imagens, destacando espaços e detalhes que não eram percebidos até então e que o olhar através do visor pode revelar. Como ressaltamos na fala dos estudantes ${ }^{3}$ mencionados, sobre a câmera possibilitar um novo olhar e sobre o desafio de colocar em uma imagem aquilo que se pensa sobre a escola:

3 Para manutenção do sigilo, os participantes são identificados na pesquisa com a letra maiúscula "E", seguido de números (Ex. E1, E2, E3...). As escolas receberam a denominação: "X" e "Y", e os números $9^{\circ}$ e $3^{\circ}$ foram utilizados para concluintes do Ensino Fundamental e Médio. 
Achei interessante, porque é outra visão que tu tem, às vezes a gente tira com o celular e coisa... dai parece que já é automático. Com a câmera, dai tu olha com outro olhar ( $X$, $3^{\circ}$ ano, E3).

É interessante isso de criar uma foto para definir uma parte da escola ou algo, um conceito que tu tenha da escola, porque é tranquilo para mim (risos), é tranquilo chegar e falar o que eu acho, não acho, deixo de achar, mas mostrar a imagem, captar alguma coisa não é a mesma coisa, tipo... é difícil fazer essa transição (X, $3^{\circ}$ ano, E2).

Foram trinta e cinco clicks sobre uma mesma instituição: a escola. Contudo, foram trinta e cinco olhares diferentes sobre ela, "as diferentes observações sobre uma mesma instituição" (REGO, 2005, p. 349). Espaços como a biblioteca, quadra de esportes, área coberta e elementos como livros, globo terrestre, mesas, bancos e classes foram capturados nas produções dos estudantes. Entre os primeiros destaques, desponta com ênfase os livros e a biblioteca, sendo quinze fotografias produzidas dentro desse espaço. Os estudantes apontaram a biblioteca como um lugar de conhecimento, sabedoria e, ao mesmo tempo, um espaço onde gostam de estar, como podemos ver na imagem que segue:

Figura 1: Conhecimento é a base de tudo

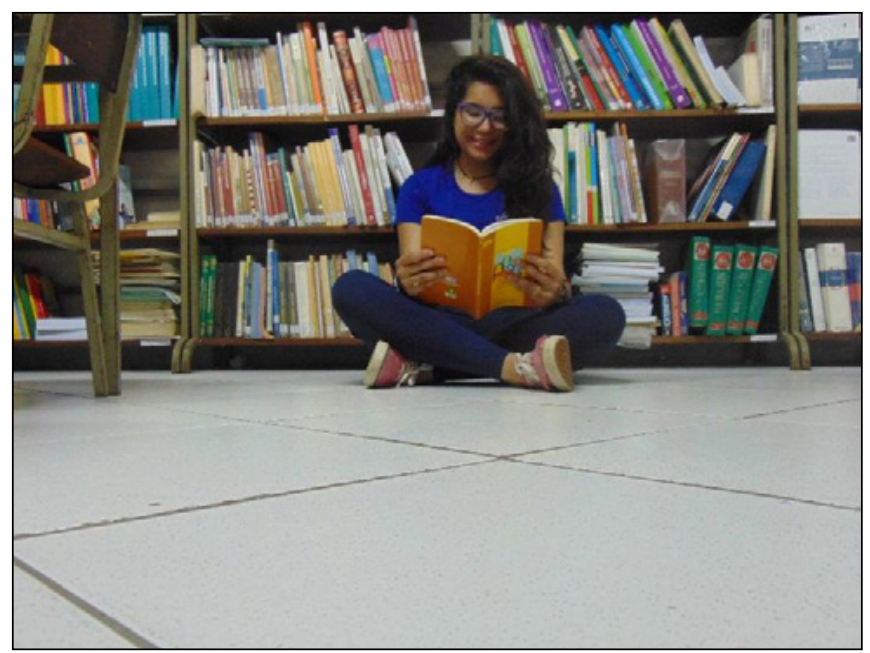

Fonte: fotografia produzida por E9 $\left(9^{\circ}\right.$ ano, $\left.\mathrm{Y}\right)$

Nessa imagem, a estudante do $9^{\circ}$ ano posicionou a câmera no chão, usando o temporizador para produzir uma fotografia em que ela mesma aparecesse. Está sentada no chão, na frente de uma estante de livros e segura na mão uma obra de capa laranja e amarela - a única informação possível de se ler é a sigla "MEC" (Ministério da Educação e Cultura), escrita na contracapa. Seu rosto exibe uma alegria, por meio de um sorriso e de um olhar direcionado ao livro. 
Percebemos que para os estudantes o livro está muito ligado ao conhecimento, por meio do qual podemos ressaltar a função pedagógica da escola: trata-se de um lugar de aprender. Para eles, este é um suporte importante no processo de aprendizagem, assim como enfatizado na legenda: "Conhecimento é a base de tudo". A respeito da mesma imagem, a discussão seguiu sobre a valorização dos livros e do espaço da biblioteca: os estudantes sinalizaram que ler o livro não é sinônimo de obter conhecimento, mas que ao lerem o livro o mesmo desperta neles uma busca de conhecimento. Atribuíram importância também à biblioteca, pois dizem se sentir acolhidos naquele ambiente. Como podemos vislumbrar nas falas que seguem:

[...] E aí a gente pensou na biblioteca, porque a biblioteca é muito importante na escola, principalmente porque a biblioteca nos dá os livros, mas não o conhecimento $\left(Y, 9^{\circ}\right.$ ano, E9).

Tem uma coisa que ninguém precisa te obrigar a fazer, que eu sei que vem da tua própria vontade: ir ali na biblioteca, pegar um livro e estudar (Y, $9^{\circ}$ ano, E5).

Os estudantes destacaram, também, o quanto consideram importante o papel da escola no incentivo à leitura e os benefícios desse hábito para os jovens, como por exemplo, melhorar a escrita e a forma de pensar:

E além disso, a leitura, quanto mais tu ler, tu melhora tua leitura e também te ajuda na base de escrever ( $Y, 9^{\circ}$ ano, E5).

Quando tu pega um livro, tu olha para a capa, pode ter uma ideia do que ele fala. Mas, tu nunca vai saber mesmo, realmente, o que tem nele mesmo se tu não ler ( $Y, 9^{\circ}$ ano, E3). É... falta incentivo, tipo... eu não ia ler uma coisa que eu era obrigada, mas se as pessoas me incentivassem, eu teria mais vontade de fazer isso $\left(X, 3^{\circ}\right.$ ano, E7).

Figura 2: O lugar da sabedoria

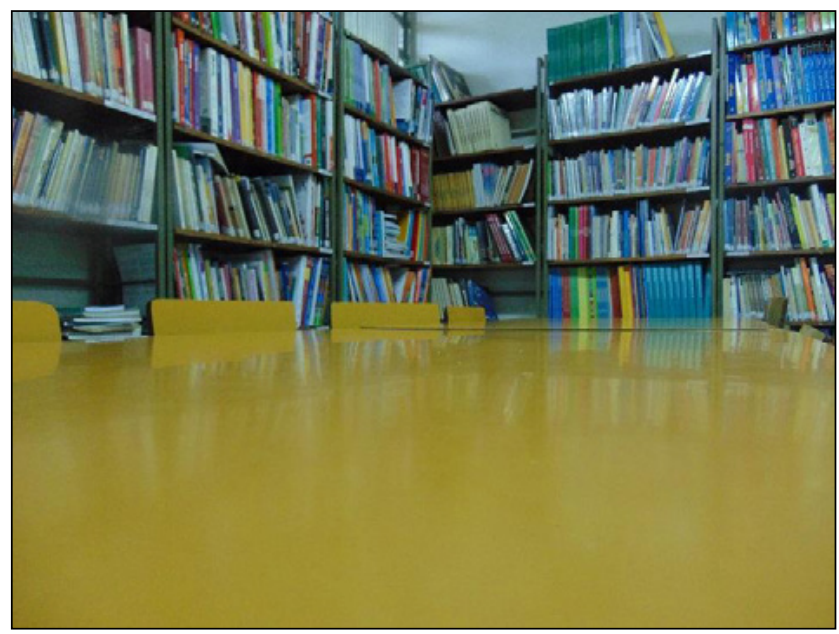

Fonte: fotografia produzida por E7 ( $9^{\circ}$ ano, $\left.\mathrm{Y}\right)$ 
$\mathrm{Na}$ segunda imagem, o destaque é o espaço da biblioteca. A câmera posicionada em cima da mesa, também de um ângulo diferente, reflete na mesma os livros que estão dispostos nas estantes. Os livros aparecem no horizonte, como se essa fosse a função deles: estar sempre lá, à mão e ao mesmo tempo distantes - pois uma mesa os separa do alcance direto do leitor (conforme o ângulo proporcionado na visão da fotografia). Também destacamos as mesas vazias, enquanto as prateleiras encontram-se repletas. Não vemos, nesta fotografia, estudantes usufruindo desse espaço de "sabedoria". Contudo, nas falas dos estudantes, há uma valorização deste lugar. As prateleiras estão cheias de livros, propondo que os estudantes usufruam desse espaço de "sabedoria":

A biblioteca é um dos locais aqui da escola que eu mais gosto de ficar, pois como gosto muito de ler, gosto de ir até lá e retirar livros, já li quase todos da biblioteca (Y, $9^{\circ}$ ano, E8).

E7: A biblioteca nunca vai deixar de ser útil na vida, dentro de uma escola, dentro da escola... nunca vai deixar de ser útil!

E4: A biblioteca é um lugar tão útil que tem até fora da escola, né? (Y, $9^{\circ}$ ano).

A imagem seguinte foi produzida igualmente no espaço da biblioteca, com a câmera posicionada no chão. O estudante fotografou, de baixo para cima, o globo terrestre, destacando nele a América do Sul, continente em que vive. Ao lado do globo, percebemos um dos pés da mesa e de duas cadeiras ao lado. Atrás, pequenas prateleiras de livros compõem o cenário:

Figura 3: Relação entre conhecimento, cultura e pessoas

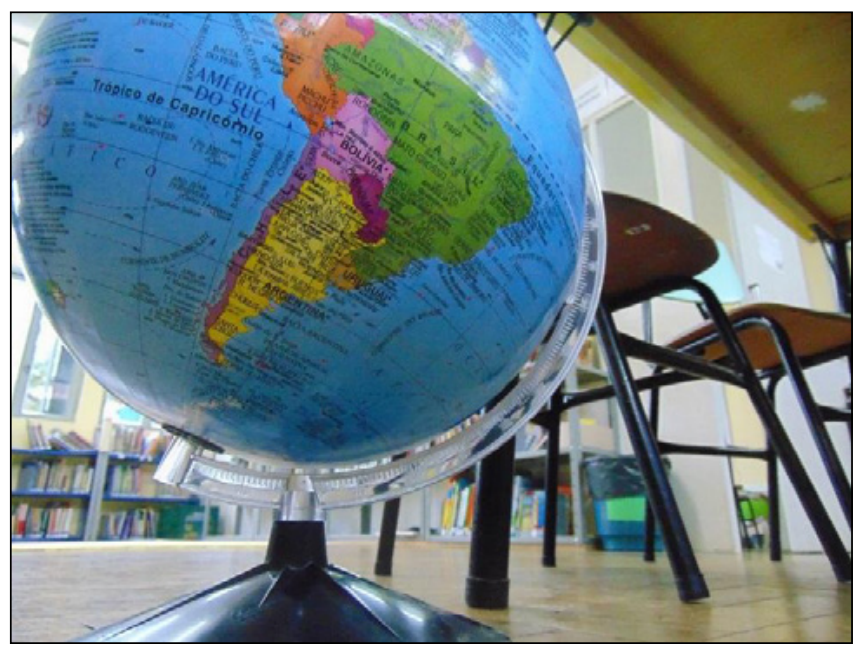

Fonte: fotografia produzida por E6 ( $3^{\circ}$ ano, $\left.\mathrm{X}\right)$.

Ao discutir a fotografia (FIGURA 3), apontamentos sobre as funções políticas e sociais surgiram e foram igualmente atribuídas à escola, conforme os excertos abaixo: 
É um equilibrio entre o conhecimento, a cultura e o relacionamento ( $X, 3^{\circ}$ ano, E5).

Comecei a pensar no meu primeiro contato com o mundo além do que eu conhecia em casa: foi com a escola, principalmente através dos livros e da base teórica que os professores me ofereceram e a interação entre culturas diferentes (...). Então, eu me tornei uma cidadã do mundo, assim tipo... adaptada a conviver com pessoas diferentes, também foi através da escola $\left(X, 3^{\circ}\right.$ ano, E4).

Podemos perceber, na imagem a seguir (FIGURA 4), uma ênfase à função social da escola. $\mathrm{Na}$ foto, aparece em destaque duas estudantes sentadas em um banco, conversando amigavelmente, em um espaço aberto, que não é o da sala de aula. As jovens estão centralizadas na imagem, com as pernas cruzadas, quase entrelaçadas, em direção a elas mesmas. O chão, de pedras, lembra o espaço do pátio - ali podemos visualizar o desenho de uma amarelinha, brincadeira infantil que parece estar em consonância com a pintura do banco em que as jovens estão sentadas. A fotografia permite entender que as duas estudantes são amigas e estão em um momento de conversa, intimidade, que são próximas uma da outra, atrelando à escola um campo de significados que vai além de sua função pedagógica e que se pauta, também, por criar e estabelecer vínculos de amizade, tão importantes para os jovens estudantes no espaço da escola. Segundo Schwertner (2010, p. 199):

[...] a escola configura-se seguramente como um espaço privilegiado e fundamental para o surgimento de novas amizades e local de encontro, especialmente para alunos mais jovens. Trata-se, então, de investir na escola como abertura de espaço para pensar sobre uma nova ética da amizade, para enfatizar os laços de amizade como um processo e não como mero "sentimento natural".

Figura 4: Grandes amizades

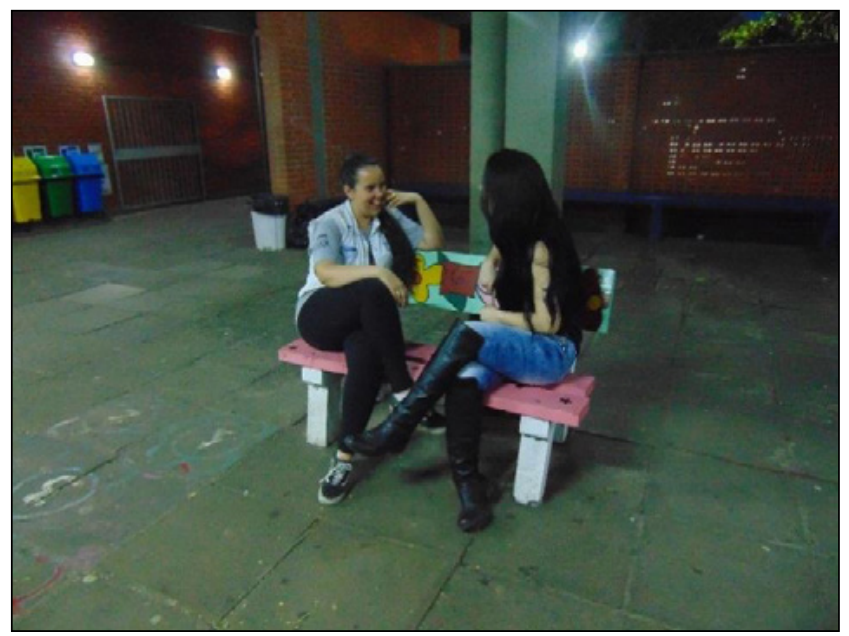

Fonte: fotografia produzida por E6 ( $3^{\circ}$ ano, $\left.Y\right)$. 
$\mathrm{E}$, segundo uma das estudantes, a importância conferida às relações interpessoais, o destaque às amizades iniciadas no espaço da escola sinaliza algo que pensa em manter "para além dos muros escola":

(...) O que eu vou levar da escola, claro, o ensinamento dos professores é muito importante, mas a amizade, acredito eu, é a mais importante, porque vou levar para o resto da vida (Y, $3^{\circ}$ ano, E5).

Destacamos nas falas dos jovens estudantes do $9^{\circ}$ ano (escola $Y$ ), a escola com um papel acolhedor, uma "segunda casa", em que os estudantes convivem mais tempo com professores e colegas do que sua própria família.

\footnotetext{
E8-Que a gente convive mais aqui do que em casa.

E9 - Na escola está todo mundo, tem os professores que a gente gosta, os que a gente não gosta... Mas, mesmo assim... a escola é minha segunda casa.

E5 - Tem assuntos que a gente fala aqui que se a gente for falar em casa pros nossos pais eles não vão entender, não vou compreender...
}

Outros elementos apontados pelos estudantes remetem ao grupo de colegas como fator importante para a aprendizagem, descentralizando o saber que seria remetido apenas à figura do professor, ao afirmar ser possível aprender também com os colegas. Eles sugerem que, às vezes, a linguagem mais simples que o colega utiliza e a forma como lhe explica, é mais fácil de compreender do que a linguagem empregada pelo professor. Além disso, aprender por meio dos colegas e entre eles, faz com que seja possível perceber diferentes maneiras de olhar para um mesmo tema, para um mesmo assunto e para a resolução de problemas de múltiplas formas.

$\mathrm{Na}$ imagem a seguir (FIGURA 5), uma das poucas produzidas dentro do espaço da sala de aula, percebemos alguns estudantes sentados nas cadeiras, com as classes aproximadas, como se estivessem realizando um trabalho em grupo. Outros dois estudantes estão em pé e conversam com outros que estão sentados. Algumas classes e cadeiras aparecem desocupadas na fotografia. A luz branca e forte, que ilumina o espaço, também reflete no piso verde da sala de aula. As janelas, de cor azul, encontramse entreabertas e a cortina aparece rente à parede; contudo, pouco se pode enxergar através das janelas basculantes. 
Figura 5: Fazendo em grupo que se aprende

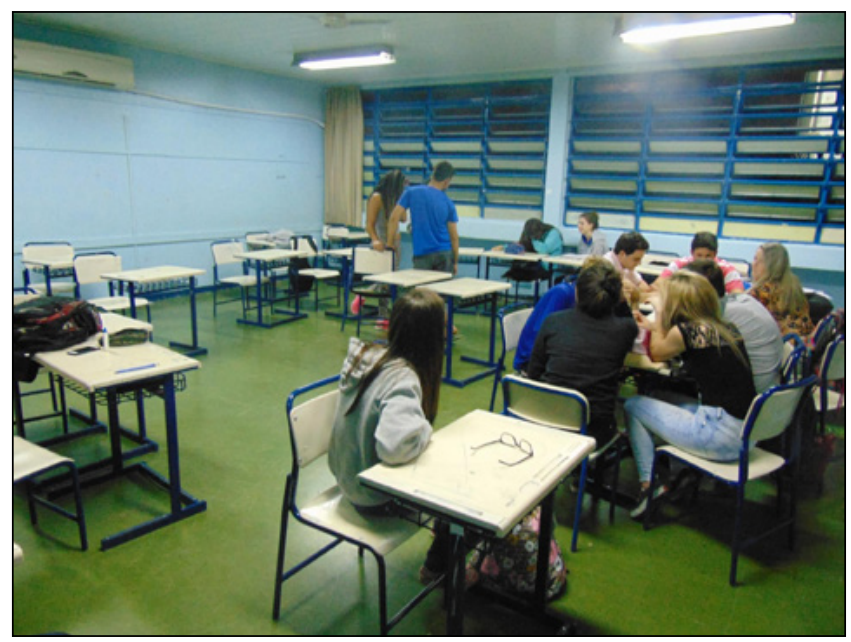

Fonte: fotografia produzida por E3 (3º ano, Y).

Sobre a imagem, a discussão seguiu entre os estudantes:

O que eu quis representar com a imagem é que em grupo os estudos se tornam mais interessantes, onde cada um pode ensinar um pouco do que aprendeu para o outro. Muitas vezes os alunos não entendem o conteúdo que o professor passou, e é ai que entram os colegas. Eles podem ensinar conforme entenderam a matéria para seus colegas, porque não existe uma única maneira de aprender, são várias maneiras, e eu acho bacana isso porque torna o estudo mais interessante (Y, $3^{\circ}$ ano, E3).

Os estudantes, aqui, parecem chamar atenção para o fato de aprender no coletivo e com os colegas - destacando um processo de educação que se faz entre os sujeitos e não individualmente. Diferentemente do apontado por Biesta (2013, p. 42), os jovens estudantes parecem compreender e enfatizar a "linguagem da educação", que toma os encontros e as trocas como cruciais para seu desenvolvimento: "Questões sobre quem somos e sobre quem desejamos nos tornar por meio da educação, embora de imensa importância para nós mesmos, são sempre questões sobre nossas relações com os outros e sobre nosso lugar no tecido social".

Torna-se importante destacar que nesta mesma fotografia visualizamos, bem ao centro, uma estudante que está sozinha, afastada do grupo e que os observa. Os óculos estão depositados sobre a mesa: teria a estudante desistido de se juntar ao grupo? Desistido de estudar naquele momento? Poderia ela aprender sozinha? Mas a própria legenda convoca: "fazendo em grupo que se aprende". Esta imagem pode nos remeter a uma discussão sobre os possíveis processos de exclusão que o espaço da escola também enfrenta. 
Até agora, destacamos as imagens que produziram discussões sobre as funções pedagógicas, políticas e sociais da escola, com destaque para um processo de aprendizagem que acontece também entre os pares. Contudo, podemos também apresentar algumas denúncias que os estudantes não se furtam de fazer acerca da escola.

$\mathrm{Na}$ imagem que veremos a seguir (FIGURA 6), podemos destacar a postura dos estudantes concluintes do Ensino Médio sobre o momento de finalização da escolarização e todo o movimento crítico que a acompanha. Ao contrário do que muitas vezes é dito, de que o jovem estudante não sabe se posicionar, não sabe discutir, percebemos que eles também estão preocupados com o que está sendo feito da escola, que eles atribuem um significativo valor a ela e querem, sim, discutir sobre este espaço e sobre o que ali acontece.

A Estudante 5 fotografou as mãos da colega segurando uma grade; no outro lado desta divisória, percebemos o ginásio da escola: vemos uma quadra, uma cesta de basquete, paredes de tijolos amarelados e que demarcam o local. Visualizamos igualmente uma luz intensa que entra pelas janelas alocadas na parte superior da imagem.

Figura 6: Liberdade ou prisão?

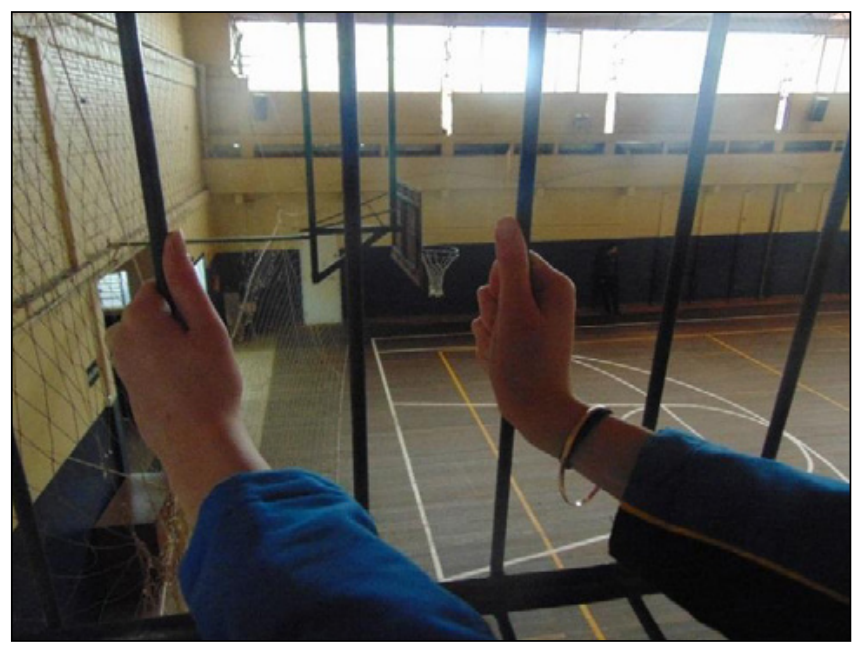

Fonte: fotografia produzida por E5 ( $3^{\circ}$ ano, $\left.\mathrm{X}\right)$.

Podemos destacar esta como a única fotografia que apresenta uma legenda em forma de pergunta, indagando: "Liberdade ou prisão?". As grades nos remetem a um espaço confinado, a algo que aprisiona, que separa dois locais. Seria o lado em que os braços se encontram que seria o espaço aprisionado? A quadra de esportes parece nos remeter a uma ideia de liberdade, de movimento, de possibilidades de andar, correr, jogar. O diálogo entre os estudantes do $3^{\circ}$ ano, que seguiu à discussão sobre a imagem pode ser acompanhado na sequência: 
E5 - Eu fui, assim, bem radical nessa foto. Tipo, eu quis dizer que na verdade, às vezes, eu quis tipo... mostrar uma parte do colégio, não toda parte, tem muita coisa boa também. Mas eu quis dizer que às vezes o colégio meio que te aprisiona a... por exemplo, estudar uma coisa e entender aquilo daquela forma e que não pode ter outra forma de olhar aquilo. Entendeu?

E2 - (...) Porque, realmente, também acho que a escola em alguns aspectos pode aprisionar e fazer o teu pensamento de uma forma, sendo que não precisa ser assim, pode ter uma outra forma teu pensamento e ele não ser errado. E isso, sabe, tem uma imagem que eu vi uma vez que era uma filinha de crianças e uma pessoa cortando as asas delas, e era a escola, no caso, cortando. Eu acho que essa imagem se compara a essa foto.

E6 - Se tem que passar tanto tempo, então por que às vezes a gente não se sente bem aqui dentro? Se tem que passar tanto tempo, então deveria ser um lugar que a gente se sentisse bem!

$\mathrm{Na}$ tentativa de normalizar, homogeneizar, disciplinar os estudantes, as escolas acabam não possibilitando oportunidades para pensar ou problematizar aquilo que estão vivenciando - e que, no caso dos estudantes concluintes do Ensino Médio, remete a mais de 10 anos de escolarização. O esperado é que todos pensem e se comportem da mesma forma, como assinala Rego (2003, p. 66):

O convívio escolar pressupõe o cumprimento de uma série de regras e códigos de conduta por parte dos alunos. De modo geral, valorizam-se os alunos considerados disciplinados, geralmente os que são capazes de respeitar, acatar e obedecer, sem questionamento e de modo autônomo, o conjunto de preceitos e regras escolares de comportamento.

Os jovens estudantes questionam o tempo (longo) que passam dentro da escola, e assinalam que muitas vezes não se sentem bem nesse espaço. Eles não dizem que não querem ir para escola ou que não atribuam valor a sua existência; pelo contrário, eles afirmam que a escola deve ser um lugar em que se sintam bem, onde suas ideias e pensamentos sejam respeitados por todos - as discussões anteriores apontam muito para tais atribuições de valores pelos próprios estudantes. Percebemos uma duplicidade nos discursos dos estudantes que afirmam o quanto, muitas vezes, a escola pode proporcionar outras vivências, novas formas de olhar e compreender e que, outras vezes, "pode aprisionar o pensamento", exigindo que os estudantes pensem apenas de uma forma. Ao mesmo tempo que dizem que a escola "amplia", também afirmam que ela "aprisiona”. E esse discurso confirma a importância da escola em proporcionar momentos de discussão com os jovens, oportunizando espaços de trocas, como destacam Klein e Arantes, que enfatizam o leque de possibilidades e a importância que a escola tem na vida dos jovens:

A ideia de possibilidades vitais é relevante à compreensão da importância que a escola pode assumir na vida dos jovens. Para os sujeitos que a frequentam, essa instituição apresenta-se como uma circunstância dada de vida capaz de oferecerlhes um leque de possibilidades (KLEIN; ARANTES, 2016, p. 136). 
Ao final, destacamos o fato de os jovens estudantes dizerem, a todo momento, que têm vozes e que desejam que elas sejam escutadas por todos que compõem o cenário da escola, entre os estudantes, professores, gestores e família.

\section{CONSIDERAÇÕES FINAIS}

Ao analisar as imagens como forma potente de produção discursiva desses estudantes, percebe-se que escola é um lugar que extrapola a função de transmitir conhecimento ou de socializar a criança e o jovem. O discurso que se percebe, muitas vezes, é a obrigatoriedade de dar conta de todos os conteúdos, principalmente no terceiro ano, em que os estudantes prestam vestibular e o Exame Nacional do Ensino Médio (ENEM). Com isso, a escola acaba deixando de lado momentos de reflexão: as discussões em grupo, debates, enfim, o que vem sendo trazido pelos estudantes no momento dos grupos focais realizados por esta investigação. Destacamos o desejo dos jovens estudantes em discutir sobre a escola, em pensar formas e papeis que ela tem desempenhado e que acreditam que deveria desempenhar.

Neste sentido, para os estudantes, a escola tem como funções principais incentivar e estimular a busca de conhecimento, concentrando nos livros e no espaço da biblioteca esta atenção. Como local que difunde a cultura e possibilita encontros com as diferenças, a escola também tem suas funções políticas e sociais destacadas: tornar-se cidadãos do mundo é um dos aspectos ressaltados pelos jovens. Igualmente, a escola como espaço de vinculação entre os colegas, de parceria e de amizade são também enfatizados. A normatização e a homogeneização propostas pela escola não deixaram de ser evidenciadas nas imagens, perguntando-se pela equação liberdade ou prisão.

Ser jovem e estar na escola, valorizar o olhar que ele tem sobre a escola, o que pode contribuir e falar sobre este espaço em que convive, no tempo presente. Este que é o tempo do jovem também, que solicita ser reconhecido naquilo que está vivendo, que está pensando, que está se perguntando - e não naquilo que viveu e menos ainda naquilo que virá a ser. Como afirmam Masschlein e Simons (2014), vozes às quais nos sintonizamos, seguimos acreditando no espaço potencial da escola, em sua possibilidade de reinvenção:

Reinventar a escola se resume a encontrar formas concretas no mundo de hoje para fornecer "tempo livre" para reunir os jovens em torno de uma "coisa" comum, isto é, algo que aparece no mundo que seja disponibilizado para uma nova geração (p. $11)$.

A pesquisa segue em andamento, buscando contribuir e ampliar a discussão sobre as funções da escola básica na atualidade, por meio do olhar criativo e inquisidor de jovens estudantes concluintes do Ensino Médio e Fundamental. 


\section{REFERÊNCIAS}

ALVES, Nilda; SGARBI, Paulo. Espaços e imagens na Escola: Rio de Janeiro: DP\&A. 2001.

AQUINO, Júlio G. Do cotidiano escolar: ensaios sobre a ética e os seus avessos. São Paulo: Summus, 2000.

BALL, Stephen J. The education debate. Bristol: Policy Press, 2008.

BANKS, Marcus. Dados visuais para pesquisa qualitativa. Tradução de José Fonseca. Porto Alegre: Artmed, 2009.

. Visual methods in social research. London: Sage, 2001.

BIESTA, Gert. Para além da aprendizagem: educação democrática para um futuro humano. Belo Horizonte: Autêntica, 2013.

COMPTON, Mary; WEINER, Lois. The global assault on teaching, teachers, and their unions: stories for resistance. New York: Palgrave MacMillan, 2008.

FISCHMAN, Gustavo. Reflections about images, visual culture, and educational research. Educational Researcher, vol. 30, no 08, 28-33, 2001.

FISCHMAN, Gustavo; SALES, Sandra R.: Iconoclash: reflexões sobre a cultura visual e pesquisas em Educação. Educação, v. 37, n. 3, p. 423-432, 2014. Disponível em: <http:// revistaseletronicas.pucrs.br/ojs/index.php/faced/article/view/18151/12451>. Acesso em: 13 de junho de 2016.

FOUCAULT, Michel. Microfísica do poder. Rio de Janeiro: Graal, 2015.

. A Arqueologia do Saber. Rio de Janeiro: Forense Universitária, 2002.

GATTI, Bernadete. Grupo focal na pesquisa em ciências sociais e humanas. Brasília: Liber Livro, 2005.

KLEIN, Ana Maria; ARANTES, Valeria Amorim. Projetos de Vida de Jovens Estudantes do Ensino Médio e a Escola. Educação \& Realidade, v. 41, n. 1, p.135-154, 2016. Disponível em: <http://www.seer.ufrgs.br/index.php/educacaoerealidade/article/view/56117/36234>. Acesso em: 13 de junho de 2016.

LARROSA, Jorge. Pedagogia profana: danças, piruetas e mascaradas. Belo Horizonte: Autêntica, 2000.

. Linguagem e educação depois de Babel. Belo Horizonte: Autêntica, 2004.

MASSCHLEIN, Jan; SIMONS, Maarten. Em defesa da escola. Belo Horizonte: Autêntica Editora, 2014.

PEREIRA, Beatriz Prado; LOPES, Roseli Esquerdo. Por que ir à escola? Os sentidos atribuídos pelos jovens do ensino médio. Educação \& Realidade, v. 41, n.1, p.193-216, 2016. Disponível em: <http://www.seer.ufrgs.br/index.php/educacaoerealidade/article/ view/55950/36239>. Acesso em: 13 de junho de 2016. 
REGO, Teresa Cristina. Memórias de escola: cultura escolar e constituição de singularidades. Petrópolis: Vozes, 2003.

SALES, Celecina Veras; VASCONCELOS, Maria Aurilene de Deus Moreira. Ensino Médio Integrado e Juventudes: desafios e projetos de futuro. Educação \& Realidade, v. 41. n. 1, p. 69-90, 2016. Disponível em: <http://www.seer.ufrgs.br/index.php/educacaoerealidade/ article/view/56094/36245>. Acesso em: 13 de junho de 2016.

SCHWERTNER, Suzana F. Laços de amizade: Modos de relacionamento jovem em tempos de conectividade. 212 f. + Anexos. Tese (doutorado) - Universidade Federal do Rio Grande do Sul. Faculdade de Educação. Programa de Pós-Graduação em Educação, Porto Alegre, 2010. Disponível em: <https://www.lume.ufrgs.br/bitstream/handle/10183/21860/000738820. pdf?sequence=1>. Acesso em: 13 de junho de 2016 .

SIBILIA, Paula. Redes ou paredes: a escola em tempos de dispersão. Rio de Janeiro: Contraponto, 2012.

SPERB, Paula. Inspirado em SP, estudantes ocupam 20 escolas no Rio Grande do Sul. Folha de S. Paulo, São Paulo, 15 mai. 2016. Disponível em: <http://www1.folha.uol.com. br/cotidiano/2016/05/1771829-inspirados-em-sp-estudantes-gauchos-ocupam-20-escolas. shtml>. Acesso em: 02 jun. 2016

TOMAZELA, José Maria. Estudantes ocupam escola técnica em São Carlos, interior de SP. Estadão, Brasília, 23 mai. 2016. Disponível em: <http:/educacao.estadao.com.br/noticias/ geral,estudantes-ocupam-escola-tecnica-em-sao-carlos--interior-de-sp,10000053013>. Acesso em: 02 jun. 2016.

TORRE, Daniela; MURPHY, Joseph. A different lens: changing perspectives using PhotoElicitation Interviews. Educational Policy Analysis Archives, v. 23, n. 111, p. 1-23, 2015. Disponível em: <http://epaa.asu.edu/ojs/article/view/2051/1689>. Acesso em: 13 jun. 2016.

VETORAZZO, Lucas. No Rio, 67 escolas estão ocupadas por alunos que pedem melhores condições. Folha de S. Paulo, São Paulo, 04 mai. 2016. Disponível em: <http://www1.folha. uol.com.br/educacao/2016/05/1767560-no-rio-67-escolas-estao-ocupadas-por-alunos-quepedem-melhores-condicoes.shtml>. Acesso em: 02 jun. 2016. 